\title{
A Atitude dos Universitários em Relação ao Profissional de Limpeza Urbana
}

The Attitude Of Academics In Relation To Urban Cleaning Workers

La Actitud De Los Universitarios Con Relación Al Profesional De Limpieza Urbana
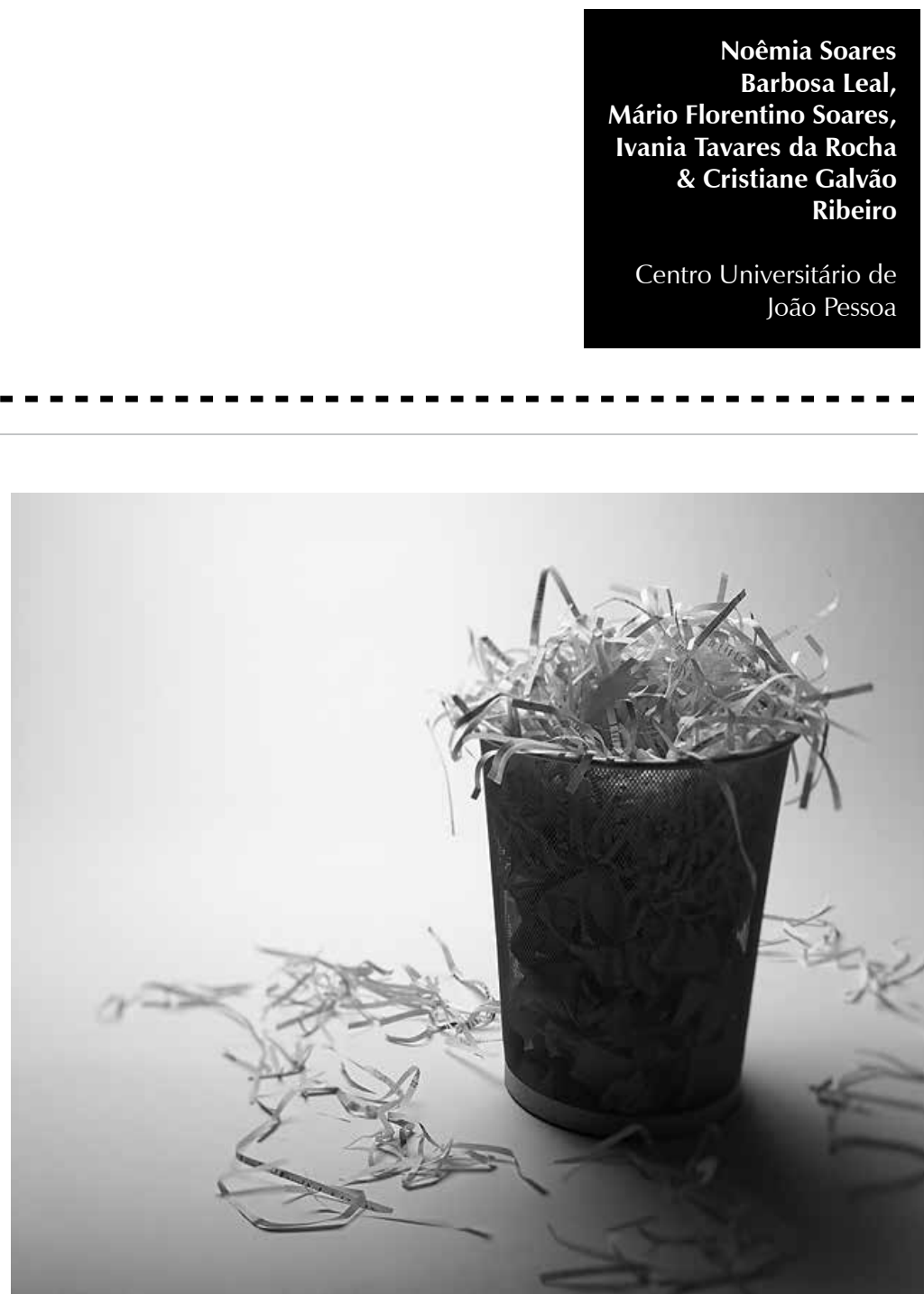
Resumo: Com o objetivo de identificar as atitudes dos universitários das redes pública e privada frente ao profissional de limpeza urbana (gari), este estudo apresenta uma pesquisa de campo do tipo descritiva, realizada com 200 estudantes universitários, sendo 100 de uma universidade pública e 100 de uma universidade privada na cidade de João Pessoa-PB. A coleta de dados foi feita por meio de escalas de atitudes, motivação e desejabilidade social, adaptadas, quando preciso, ao ofício de gari e analisadas por meio do pacote estatístico SPSS, em sua versão 15.0 utilizando-se da estatística descritiva e inferencial. Discutem-se temáticas de amplo interesse da Psicologia social, tais como preconceito, atitude, estereótipo e discriminação bem como seus impactos na relação homem-trabalho. Os resultados encontrados revelam que as mulheres são mais conscientes quanto à importância da profissão gari para o bom funcionamento público, bem como que há preconceito nas relações sociais, e, embora este seja expresso de modo sutil, ainda marca negativamente as relações sociais.

Palavras-chave: Preconceito. Discriminação social. Gari. Atitudes. Estigma.

Abstract: Aiming at identifying the attitudes of graduate students from both public and private universities in relation to urban cleaning workers (garbage men), this study presents a descriptive field research carried out with 200 graduate students: 100 from a public university and 100 from a private one in João Pessoa, PB. Data collection was done by means of attitude, motivation and social desirability scales which were adapted, when it was necessary, for the garbage men occupation and then analyzed through the statistical package SPSS for Windows 15.0, using descriptive and inferential statistics. Issues of great interest to social psychology, such as prejudice, attitude, stereotype and discrimination, as well as their impacts in man-work relation were discussed. The results show that women are more aware of the importance of garbage men occupation for proper public functioning and that there is prejudice in the social relations, that although it is expressed in a subtle way, it still plays a negative role in social relations.

Keywords: Prejudice. Social discrimination. Street Cleaners. Attitudes. Stigma.

Resumen: Con el objetivo de identificar las actitudes de los universitarios de las redes pública y privada frente al profesional de limpieza urbana (barredor), este estudio presenta una investigación de campo del tipo descriptiva, realizada con 200 estudiantes universitarios, siendo 100 de una universidad pública y 100 de una universidad privada en la ciudad de João Pessoa-PB. La recolección de datos fue realizada por medio de escalas de actitudes, motivación y deseabilidad social, adaptadas, cuando preciso, al oficio de barredor y analizadas por medio del paquete estadístico SPSS, en su versión 15.0 utilizándose de la estadística descriptiva e inferencial. Se discuten temáticas de amplio interés de la Psicología social, tales como prejuicio, actitud, estereotipo y discriminación así como sus impactos en la relación hombre trabajo. Los resultados encontrados revelan que las mujeres son más conscientes en relación a la importancia de la profesión barredor para el buen funcionamiento público, así como que hay prejuicio en las relaciones sociales, y, aunque éste sea expreso de modo sutil, aún marca negativamente las relaciones sociales.

Palabras clave: Prejuicio. Discriminación social. Barrederos. Actitudes. Estigma.

O preconceito, impressões estereotipadas formuladas sobre pessoas ou determinados grupos sociais, está presente nos diversos contextos das relações sociais. A partir da percepção social, o homem forma impressões sobre si mesmo e sobre os outros. Tais impressões partem de sua interação com o mundo e são organizadas em nível cognitivo, estando relacionadas a afetos positivos ou negativos (Camino, Maciel, Brandão, \& Gomes, 1996). Em função desses aspectos, o sujeito desenvolve uma predisposição para agir favoravelmente ou não frente às pessoas ou aos objetos presentes em seu meio social. Tais informações são imbuídas de uma carga afetiva que predispõe o indivíduo a assumir determinado comportamento, denominado atitude (Rodrigues, Assmar, \& Jablonski, 2001).

\section{Atitudes}

A atitude é um dos temas mais antigos e mais estudados em Psicologia social, de modo que seus conceitos e formas de avaliação serviram para dar identidade a essa área do conhecimento. Na percepção de Allport (1954), a atitude é um estado neurológico e mental de alerta, organizada através da experiência e capaz de exercer uma influência mentora ou dinâmica sobre a resposta da pessoa a todos os objetos e 
Adquiridas por meio da aprendizagem, as atitudes constituemse de três componentes, a saber, o cognitivo

(pensamentos e crenças), o afetivo (sentimentos de atração ou rejeição) e o comportamental (tendência de reação do indivíduo diante do objeto da atitude), podendo ser positivas ou negativas (Pisani, Bisi, Rizzon, \& Nicoletto, 1985). situações a que está relacionada. Ela é uma resposta subentendida, produtora de tensão e considerada socialmente significativa no meio em que o indivíduo está inserido.

Nesse sentido, as atitudes não nascem no vazio social, mas constituem uma construção individual do sujeito, porém de caráter aprendido e fortemente influenciada por crenças, valores, sentimentos e experiências socialmente partilhadas, correspondendo necessariamente a objetos específicos que estão presentes ou que são lembrados devido a um indício (Lima, 2002). Na medida em que não são diretamente observáveis, as atitudes são consideradas um construto hipotético, com uma tendência psicológica com certa estabilidade temporal, e expressam-se por meio do julgamento avaliativo, que tem como características a direção (favorável x desfavorável), a intensidade, que opõe as posições extremas às mais fracas, e a acessibilidade, que é a probabilidade de ser ativada automaticamente da memória quando o sujeito se depara com o objeto atitudinal (Eagly \& Chaiken, 1993 como citado em Lima, 2002).

Adquiridas por meio da aprendizagem, as atitudes constituem-se de três componentes, a saber, o cognitivo (pensamentos e crenças), o afetivo (sentimentos de atração ou rejeição) e o comportamental (tendência de reação do indivíduo diante do objeto da atitude), podendo ser positivas ou negativas (Pisani, Bisi, Rizzon, \& Nicoletto, 1985). Conforme Rodrigues (1998), elas envolvem o que as pessoas pensam, sentem e como gostariam de se comportar a respeito de um objeto atitudinal, sendo o comportamento determinado não apenas pelo que as pessoas gostariam de fazer mas também pelo que elas pensam que devem fazer, tendo em vista as consequências esperadas de seu comportamento.

Quanto à estrutura das atitudes, a teoria da avaliação social, de Sherif e colaboradores (1965 como citado em Lima, 2002), sugere a existência de uma escala de referência interna que cada pessoa divide em três zonas de acordo com a sua própria posição: a zona de aceitação, que inclui as crenças que o indivíduo considera aceitáveis, a zona de rejeição, para as crenças inaceitáveis, e a zona de não comprometimento, que inclui as crenças que não são consideradas nem aceitáveis nem inaceitáveis. Nesse sentido, a atitude seria o resultado das associações entre o objeto de atitude e as diversas avaliações que o indivíduo faz diante desse objeto.

Segundo Michener, DeLamater e Myers (2005), a atitude caracteriza-se por sua tendência de resistir a mudanças, de tal modo que a reação de uma pessoa confrontada a mudar sua atitude frente a um objeto ou ao comportamento de alguém é apresentar contra-argumentos que justifiquem sua atitude como correta. Tal tendência é produto do modo como as atitudes se organizam na mente, pois a atitude de uma pessoa em relação a qualquer objeto social, geralmente, não é uma unidade isolada, mas está inserida em uma estrutura cognitiva interligada a um complexo número de outras atitudes.

Os processos de formação e de mudança de atitudes estão vinculados a recursos distintos, de modo que a formação de atitudes ocorre de modo não consciente, seja por meio da aprendizagem condicionada, seja pela exposição a estímulos vivenciados como efetivamente positivos, ao passo que a mudança de atitudes costuma ocorrer na esfera da consciência (Ferreira, 2010). Assim, a mudança de atitudes pode ocorrer a partir de uma experiência direta com o objeto atitudinal, pois as atitudes de uma pessoa tornam-se passíveis de reformulações sempre que lhes são proporcionadas vivências posteriores com o objeto. Nos casos em que 
a atitude negativa é produto de estereótipos advindos de informações e de experiências limitadas e supergeneralizadas, a apresentação aos objetos a que são dispensadas atitudes negativas, cujos interesses e valores sejam comuns aos dos indivíduos, pode tornar-se um meio eficaz de estimular uma mudança social e atitudinal (McDavid \& Harari, 1980). Desse modo, ao indivíduo que apresenta, por exemplo, preconceito contra profissionais que desempenham funções consideradas subalternas, como o gari, é concedida a oportunidade de interagir com eles, visando à produção de atitudes mais favoráveis.

Outro mecanismo válido para a proposta de mudança de atitude é o desempenho de papéis, em que a pessoa adota determinado papel e age conforme as exigências sociais feitas a ele. Inicialmente, o indivíduo apenas representa e segue as prescrições condizentes ao papel; ao se tornar ciente de que suas atitudes não condizem com seu real comportamento, ele tende a justificar a nova atitude assumida, de modo a amenizar o desconforto da dissonância cognitiva que está sentindo. O resultado é a tentativa de aproximação das atitudes às ações ou ao comportamento; desse modo, percebe-se que os comportamentos afetam as atitudes, e, embora não seja possível controlar diretamente os sentimentos, presumese que estes podem ser influenciados pela modificação do comportamento (Myers, 2006). De acordo com Rodrigues (1998), a mudança de atitude torna-se necessária sempre que se busca promover o bem-estar geral da humanidade, pelo qual comportamentos negativos como o preconceito devem ser contidos para que seja possível a compreensão e a cooperação entre grupos e pessoas em conflito.

Outro aspecto importante referente às atitudes é sua função esquemática, ou seja, elas possibilitam um ambiente significativo, funcionando como guia do comportamento.
Esse esquema ou conhecimento ajuda a filtrar o complexo e significativo número de informações externas, o que permite agrupar tanto pessoas como acontecimentos em categorias, dispensando essas atitudes simplificadas e estereotipadas. Logo, as atitudes assumidas em direção a um grupo favorecem a formação de uma base para que se façam inferências sobre seus membros (Bodenhausen \& Wyer, 1985 como citado em Michener et al., 2005).

Em termos gerais, a função das atitudes é facilitar a adaptação do indivíduo ao ambiente em que está inserido. Dentre as funções mais reconhecidas pelos teóricos (Katz, 1960; Herek, 1986 como citado em Lima, 2002), as atitudes podem cumprir funções motivacionais (avaliativas e simbólicas), cognitivas e de orientação para a ação. A função motivacional avaliativa refere-se à avaliação dos custos e dos benefícios da atitude, pela qual se pressupõe que o indivíduo opta pela atitude que lhe permita o melhor ajustamento social, maximizando as recompensas sociais e minimizando as punições, ao passo que, na simbólica, o indivíduo se utiliza das atitudes como forma de transmitir seus valores e identidade, permitindo-lhe proteger-se contra conflitos internos e externos e preservar sua imagem.

Quanto às funções cognitivas das atitudes, Rodrigues salienta que é necessário ter alguma representação cognitiva do objeto para que se tenha uma atitude em relação a este. Tal função está ligada à forma como as atitudes influenciam o modo como é processada a informação, destacando-se nesse âmbito o princípio do equilíbrio e o da redução da dissonância. O primeiro foi formulado por Heider (1958/1970) com o objetivo de identificar o modo como o indivíduo percebe o meio em que vive e de que forma articula as diferentes atitudes. Já o princípio da redução da dissonância cognitiva (Festinger, 1957 como citado em Lima, 2002) pretende 
explicar a necessidade que há em todas as pessoas de encontrarem consonância entre as várias cognições que têm referentes a um mesmo objeto. Assim, sendo o estado de dissonância cognitiva psicologicamente desagradável, o organismo é impulsionado a reduzir ou a eliminar tal desconforto, o que se faz aumentando a importância das cognições consonantes ou diminuindo a importância das cognições dissonantes. Por fim, a função de orientação para a ação relaciona as atitudes com os comportamentos, sendo que Fazio e Zana (1981 como citado em Lima, 2002) sustentavam que as atitudes que se formam com base na experiência direta são mais preditoras do comportamento do que as que se baseiam na experiência indireta, visto que tornam as atitudes mais acessíveis.

Se ao assumir uma definição dos três componentes atitudinais (cognição, afeto e comportamento), o preconceito se configura como o aspecto afetivo de uma atitude negativa frente a um grupo, ou a membros de um grupo estereotipado com base nas crenças acerca de atributos a ele associadas, o preconceito, conforme Allport (1954) será definido como uma atitude hostil e, portanto, negativa. Não raro, o preconceito e o estereótipo caminham juntos, e as pessoas utilizam suas crenças estereotipadas para justificar seu preconceito em relação a integrantes de determinados grupos (Michener et al., 2005).

\section{Estereótipos e categorização}

Um subproduto imprescindível da tendência que o homem tem de tentar classificar suas experiências e de integrá-las a sistemas conceituais organizados é o fato de que objetos, acontecimentos e pessoas são, geralmente, julgados e interpretados com base em informações limitadas e com poucas características familiares. Essa tendência para agir em conformidade com informações parciais é uma parte integrante do processo formador de conceitos, e é também o início do preconceito, algo excessivamente generalizado e baseado em informações superficiais e ambíguas, ou seja, nos estereótipos (McDavid \& Harari, 1980).

Etimologicamente, o termo estereótipo deriva do grego, e corresponde ao vocábulo stereo, rígido, e a tipo, traço. A partir dessas expressões, constrói-se o significado completo, ou seja, "tornar-se fixo, inalterável", que aponta a força da rotulação (Ferreira, 1999 como citado em Melo, Giovani, \& Tróccoli, 2004). Os estereótipos são evidenciados nas relações intergrupais e intragrupais e fazem-se presentes em todas as culturas em que os componentes de um grupo compartilham as crenças estereotipadas entre si e as levam para fora do grupo. Na Psicologia social, dada a sua função articulatória entre os processos psicológicos, como os motivacionais, cognitivos e sociais, o conceito de estereótipo é abrangente e amplamente discutido, ao mesmo tempo em que se devem considerar como determinantes dos processos psicológicos aspectos históricos e ideológicos (Moreira, Costa, Raymundo, \& Araújo, 2004).

Assim, o fator determinante para a instalação do estereótipo nos indivíduos se dá pela percepção que o próprio indivíduo formula acerca do mundo exterior, onde primeiro observa o ambiente externo e dele coleta informações que facilitem um julgamento baseado em sua individualidade, para posteriormente definir o mundo segundo sua percepção. Em virtude disso, a interpretação do mundo e de seus elementos, de modo geral, está fortemente associada à cultura, que determina, de forma estereotipada, a noção interna do indivíduo sobre o mundo externo. Logo, já haveria uma opinião formada, de acordo com as experiências adquiridas anteriormente, através do contato com diferentes informações advindas da cultura, para se analisar o mundo antes mesmo de observá-lo. O mundo estaria ordenado por 
códigos, passados de geração a geração, que favoreceriam a formação dos estereótipos, que, por função, defenderiam as tradições culturais e as posições sociais (Guerra, 2002).

O estereótipo pode, então, ser definido como uma crença compartilhada de que determinados traços são característicos de um grupo social e da visão estereotipada da realidade, que, conforme Álvaro e Garrido (2006), tem sua base no processo de caracterização. Esta é o meio pelo qual a informação recebida de fora é organizada e ordenada em classes de objetos ou categorias, servindo à função de economizar esforços do sistema cognitivo no processamento de informações e de facilitar a orientação da pessoa no mundo. Assim, ao se deparar com determinado objeto, o indivíduo não reage a ele como se fosse único, antes o percebe como membro, mais ou menos representativo, de uma categoria.

Dentre as funções dos estereótipos destacadas por Tajfel (1981 como citado em Álvaro \& Garrido, 2006), destaca-se a função cognitiva, que busca minimizar as diferenças do endogrupo e maximizar as do exogrupo, ocorrendo aí o fenômeno de favoritismo endogrupal, em que a percepção que se tem do endogrupo é heterogênea, uma vez que se consegue perceber as idiossincrasias individuais. Já o exogrupo é tido como homogêneo, uma vez que só se percebe o estereótipo do grupo, ou seja, as características mais salientes, fazendo-se uma generalização e deixando-se de lado as particularidades dos indivíduos do exogrupo.

Por ser uma crença exacerbada vinculada a uma categoria, o estereótipo atua como um mecanismo justificativo para a admissão ou para a rejeição categórica de um grupo, bem como um mecanismo seletivo para que se mantenha uma percepção e um pensamento simplista (Allport, 1954). Eles orientam as interpretações e a memória, levando as pessoas a encontrarem evidências de confirmação mesmo quando elas não existem. Por isso, os estereótipos resistem a mudanças e são mais fortes quando de fato são verdadeiros, quando indivíduos desconhecidos são julgados e quando se adotam medidas políticas em relação a grupos inteiros. Os estereótipos podem influenciar sutilmente avaliações do comportamento alheio, embora haja a tendência de descartá-los do grupo quando se interpreta o comportamento de pessoas conhecidas (Myers, 2000).

\section{Preconceitos e discriminação}

Por sua vez, o termo preconceito deriva do latim praejudicium: prae significa anterior, e judicium, julgamento. Nesse sentido, o preconceito corresponde a um modo efetivo e sistemático do funcionamento mental humano que engloba um préjulgamento rígido e, ao mesmo tempo, errôneo referente a determinados grupos (Jones, 1973). Conforme estabelece Allport, o preconceito pode ser compreendido como uma hostilidade fundamentada em uma generalização errada e rígida, que pode ser apenas sentida ou expressamente aberta e direcionada a um indivíduo identificado como membro de determinado grupo ou mesmo ao grupo como um todo. No entanto, são estabelecidas diferenças entre os erros dos pré-julgamentos e os do preconceito.

Assim, se uma pessoa é capaz de corrigir um julgamento errôneo e de levar em consideração uma nova evidência, essa atitude pode ser considerada preconceito. Por isso, os pré-julgamentos só se tornam preconceitos se não forem reversíveis quando expostos a novos conhecimentos. Segundo Suman (2007), o problema se dá quando as pessoas, mesmo a par de novas informações e capacitadas para realizar uma análise das situações com as quais são confrontadas, continuam compreendendo e enxergando 
Segundo

Billing (1986), a discriminação e o preconceito estão intrinsecamente interligados, sendo o preconceito considerado o fator que desencadeia a discriminação. com maior coerência as ideias que já têm concebidas e realizadas. Nas palavras de Lima e Vala:

o preconceito é como um vírus latente ou adormecido, que corrói os tecidos sociais com violência discreta quando a norma da igualdade está saliente, mas que, quando encontra uma norma social qualquer que justifique a sua expressão mais virulenta, explode em fanatismo nacionalista e xenófobo. (2004, p. 408)

Além das bases etimológicas, ainda se pode encontrar uma diversidade de aspectos que são considerados para definir o preconceito. Em função disso, por mais que se tente relacionar, juntar ou combinar tais aspectos, corre-se sempre o risco de não se conseguir captar todo o sentido que os indivíduos empregam para tal construto. Isso se deve, provavelmente, ao fato de que as definições diferem amplamente em intensidade e no modo de expressão. No entanto, todas envolvem um sentimento negativo dirigido a um grupo particular de pessoas ou aos representantes desse grupo (Brown, 1995). Davidoff (1983) corrobora esses aspectos ao definir preconceito como uma indisposição, um julgamento prévio, geralmente negativo, dirigido a uma pessoa ou a um grupo de pessoas, sendo o seu ponto de partida a generalização superficial, o estereótipo, que exagera os traços típicos do grupo e ignora a força e as fraquezas individuais.

Como tal, o preconceito ultrapassa as crenças distorcidas, negativas e os sentimentos de antipatia sobre os grupos sociais, necessitando de meios que propiciem sua manifestação, ao que a discriminação serve como uma ferramenta. A discriminação, considerada uma atitude negativa, é frequentemente usada na tentativa de manter as características de privilégio de um grupo majoritário sobre um grupo minoritário ou indivíduo oprimido, suscitando diferentes tipos de problemas sociais (Jones, 1973).
Segundo Billing (1986), a discriminação e o preconceito estão intrinsecamente interligados, sendo o preconceito considerado o fator que desencadeia a discriminação. Esta, por sua vez, apresenta-se como condição favorável para o comportamento discriminatório, não existindo uma união metódica ou automática entre ambos, pelo contrário, discriminação e preconceito se unem no contexto social, podendo resultar da pressão por parte de um grupo e do conformismo por outro. A maneira mais produtiva de detectar as manifestações de discriminação é por meio de estudos que avaliam a percepção, a sondagem de atitudes, e por experimentos de laboratório e pesquisas de campo. Todos esses métodos apresentam vantagens e limitações na hora de medir diferentes graus de discriminação, sobretudo porque, no contexto das relações cotidianas atuais, a discriminação se apresenta de modo extremamente sutil (Pager, 2006), termo que tem sido utilizado para descrever o novo modo pelo qual o preconceito é expresso, uma vez que as normas sociais se opõem ao preconceito e exercem sobre as pessoas uma autoridade que limita certas manifestações. Essa nova forma (o preconceito sutil) evita o confronto direto com o objeto, pessoa ou grupo pelo qual se tem preconceito, tolerando os discriminados (a certa distância) e atacando-os apenas de modo indireto. Desse modo, os indivíduos demonstram conhecer as normas sociais que os controlam, mas não as interiorizam, sendo o preconceito nesses casos muito mais sofisticado e distante (Santos, Gouveia, Navas, Pimentel, \& Gusmão, 2006).

O preconceito sutil é composto por três dimensões. A primeira é a da defesa dos valores tradicionais, que se referem à percepção de que os membros do exogrupo agem de maneira incorreta e mesmo condenável na busca da realização social. 
A segunda dimensão é a do exagero das diferenças culturais, ou seja, é a percepção de que o exogrupo é culturalmente muito diferente do endogrupo. Por último, a terceira dimensão é a da negação de emoções positivas, caracterizada pela rejeição à expressão de simpatia e de admiração quanto aos membros do exogrupo (Pettigrew \& Meertens, 1995 como citado em Lima \& Vala, 2004).

Para Camino e Pereira (2002), o preconceito está implicado em uma perspectiva psicossocial, ou seja, não se pode compreender o preconceito desconectando o indivíduo de seu meio, pois perde-se a possibilidade de compreender as novas formas pelas quais ele se manifesta e também sua dinâmica nas relações sociais. Antes, compreende-se que os preconceitos se desenvolvem no seio das relações intergrupais e geralmente são marcados por relações de poder entre os grupos, desenvolvendo-se, principalmente, no interior dos grupos dominantes, e podem ser definidos como uma forma de relação assimétrica de poder que gera atitudes depreciativas, comportamentos hostis e discriminatórios em relação aos membros dos grupos minoritários ou do exogrupo, simplesmente por serem pertencentes a estes.

Costa preceitua que "o comportamento não é uma unidade atomizada, é um fenômeno total, um ente em situação" (2004, p. 87), posto que os trabalhadores pobres vivenciam relações sociais marcadas por seus desníveis, pela dominação de um pelo outros, em que os dominados não são reconhecidos por suas capacidades, pois, quanto mais baixos os cargos, menos esses trabalhadores aparecem. No caso dos profissionais de limpeza urbana, eles "não comandam ninguém, são sempre comandados. Seu cargo é o mais raso. Os garis sentem-se invisíveis" (2004, p.108).

\section{Contexto social da manifestação das atitudes, estereótipos e preconceitos}

No que se refere à relação homem-trabalho, e uma vez que foi por meio deste que o homem superou sua condição primitiva natural tornando-se um ser social, assume-se o trabalho como um elemento estruturante entre os homens, a natureza e o ambiente social, que possibilita, além da subsistência, a interação social, a inclusão social e o sentimento de pertencer a um grupo. Desse modo, o trabalho se configura como um elemento pertencente aos indivíduos que integram uma sociedade, e viabiliza a construção de uma identidade tanto profissional quanto pessoal. Dessa relação, deriva o significado essencial da sociabilidade humana, em que o exercício de uma profissão reflete a identidade de uma pessoa e caracteriza seu modo de vida (Medeiros \& Macedo, 2006).

No entanto, frequentemente, atitudes negativas, caracterizações estereotipadas e preconceitos são lançados e atribuídos às profissões sem status social, vistas como inferiores, ainda que façam parte do mercado formal, como é o caso dos garis. Como define Costa, o ofício de gari, ou varredor de ruas, é uma atividade de perfil persistentemente reservada a uma classe social subproletarizada e historicamente condenada ao rebaixamento social e político, em que as relações sociais são marcadas por seus desníveis.

Além de sofrerem a discriminação e de serem alvo constante de preconceitos, esses profissionais só tem o valor de seu trabalho percebido pela sociedade quando esse deixa de ser feito, prejudicando a saúde pública e deixando os ambientes públicos com um visual desagradável (Reimberg, Barcellon, \& Bossle, 2007). Conforme Costa (2004), é assim que esses profissionais deixam de 
ser vistos por suas capacidades ou por sua natureza humana, e passam a ser tidos como representantes de cargos determinados, como função, como ferramenta, de tal modo que são reificados, ou seja, objetificados, alienados de suas qualidades pessoais de trabalhadores; é como se o trabalho perdesse seu caráter humano. Ainda segundo esse autor:

Os garis, recebendo a carga redutora da atenção funcional, contam (...) só para o desempenho de papéis simples. (...) Só aparece o que fazem ou o que devem fazer (...) só aparecem fazeres simples, figuram personagens simples, não existem pessoas. (2004, p. 124)

Com efeito, a divisão da sociedade em classes gerou e acentuou uma divisão dos bens produzidos e dos cargos profissionais, notadamente desiguais, que põe de um lado profissões que gozam de prestígio social e, de outro, profissões caracterizadas pela servidão. Cristalizou-se uma divisão entre os homens que servem e os que são servidos, em que pesa sobre as classes pobres da sociedade o trabalho simplificado ou simples, que exige pouca ou nenhuma instrução técnica ou escolar, mas que assim mesmo é indispensável (Gonçalves Filho, 1998; Costa, 2004).

Não raro, os profissionais de limpeza urbana (garis) são utilizados como exemplo quando se quer fazer referência àquelas pessoas que não estudaram ou que não aproveitaram as oportunidades da vida. Um exemplo bem conhecido são os pais que, para intimidar seus filhos, dizem que, se não estudarem, serão lixeiros ou garis no futuro. Nesse contexto, raramente se consideram as condições sociais que levaram o indivíduo a não investir em uma carreira de status positivo ou mais bem remunerada. Devese reconhecer que fatores como o trabalho desde a infância, a distância da escola e a crença de que os pobres não têm chances, entre outros, podem ser determinantes no futuro de alguém e, ao mesmo tempo, constituírem motivos para destituir a ideia do preguiçoso por si só (Suman, 2007).

Assim, tem-se que o preconceito e as atitudes negativas podem produzir efeitos dilaceradores nas relações sociais, e só por meio da aceitação mútua do outro com sua individualidade e havendo ainda reconhecimento valorativo do seu papel na sociedade é que se torna viável um futuro mais promissor, ético, moral e harmônico. Diante dos pressupostos teóricos, este estudo teve como objetivo principal identificar as atitudes que alunos universitários dispensam ao profissional de limpeza urbana.

\section{Método}

Esta se caracterizou como uma pesquisa não experimental, do tipo descritiva, uma vez que buscou identificar as atitudes e as motivações pessoais quanto ao gari, sendo observadas as variáveis de interesse da presente pesquisa por meio de escalas de atitudes, motivação e desejabilidade social.

O método para a escolha da amostra foi a não probabilística por conveniência, com estudantes universitários das áreas de saúde, exatas e humanas, das universidades de tipo particular e pública da cidade de João Pessoa, PB.

\section{Participantes}

Participaram desta pesquisa 200 universitários, sendo 100 de rede pública e 100 de rede privada, com média de idade de 22,97 anos $(\mathrm{DP}=4,71)$, sendo $54 \%$ do sexo feminino e $46 \%$ do sexo masculino, estudantes das redes pública e privada da cidade de João Pessoa, das áreas de saúde, humanas e exatas. A seguir, será demonstrado o perfil sociodemográfico da amostra estudada: 
Tabela 1. Perfil sociodemográfico dos participantes da pesquisa

\begin{tabular}{lllllc}
\hline Sexo & $\mathrm{f}$ & $\%$ & Idade & $\mathrm{f}$ & $\%$ \\
\hline masculino & 92 & 46 & Entre 18 e 30 anos & 189 & 94,50 \\
feminino & 108 & 54 & Entre 30 e 54 anos & 11 & 5,5 \\
TOTAL & 200 & 100 & Total & 200 & 100 \\
$\begin{array}{l}\text { Tipo de } \\
\text { Universidade }\end{array}$ & $\mathrm{f}$ & $\%$ & Curso & $\mathrm{f}$ & $\%$ \\
$\begin{array}{l}\text { pública } \\
\text { privada }\end{array}$ & 100 & 50 & Humanas & 107 & 53,5 \\
& 100 & 50 & Exatas & 34 & 17 \\
Total & & & saúde & 59 & 29,5 \\
& 200 & \multirow{2}{*}{100} & Total & 200 & 100 \\
\hline
\end{tabular}

\section{Instrumentos}

Os participantes responderam um livreto composto por quatro partes, a saber:

Escalas de atitudes preconceituosas. Formulado originalmente por Martinez (1996), essa medida compõe-se de dez itens referentes a atitudes (por exemplo, admiração, hostilidade, aceitação) frente a determinados exogrupos, neste caso específico, profissionais de limpeza urbana. Para responder, o participante deveria indicar seu grau de acordo ou desacordo com relação a cada uma das atitudes expostas, e, para tanto, utilizou uma escala do tipo Likert, cujas alternativas variaram de $\mathbf{1}$ = nunca a $\mathbf{5}=$ sempre.

Escala de Motivação Interna e Externa para Responder sem Preconceito. Em sua versão original, este instrumento foi desenvolvido por Plant e Devine (1998) e utilizado por Gouveia, Souza, Araújo, Guerra e Sousa (2006) para identificar as motivações que induzem as pessoas a tentar responder de maneira não preconceituosa com relação aos negros. Contudo, para utilização neste projeto, procurou-se adaptá-la de modo a considerar tais motivações com relação aos profissionais de limpeza urbana (garis). Em suas respostas, o participante indica, por meio de uma escala de nove pontos, sendo $\mathbf{1}$ = discordo totalmente e $\mathbf{9}$ = concordo totalmente, em que medida concorda ou discorda de cada um dos itens apresentados.

Medida de desejabilidade social. Elaborada originalmente por Crowne \& Marlowe (1960) em língua inglesa, faz parte do Questionário dos 16 Fatores de Personalidade. É composta por 12 itens a serem respondidos em escala do tipo Likert, com cinco pontos, variando de 1 = nunca a $5=$ sempre, indicando em que medida cada um destes descreve o comportamento ou modo de pensar do respondente.

Caracterização da amostra. Além das medidas anteriores, foram consideradas algumas perguntas de caráter sociodemográfico (por exemplo, sexo, idade, curso) para identificação da amostra.

\section{Procedimento}

Após o contato com as universidades e a devida autorização cedida pelo Comitê de Ética para coleta dos dados, os aplicadores passaram nas salas de aula e corredores explicando os motivos 
da pesquisa e convidando os estudantes a participar. Na ocasião, foi informado aos participantes o anonimato e o sigilo de suas identidades e apresentado um Termo de Consentimento, que: (1) garantiu que a pesquisa não causaria danos ou desconfortos físicos e/ou psicológicos, (2) informou que se trata de uma participação voluntária que pode ser interrompida a qualquer momento e (3) autorizou os pesquisadores a apresentarem os resultados da pesquisa em eventos e publicações. O termo deveria ser assinado pelo participante, que, em seguida, passaria a responder os instrumentos. Uma vez que se tratou de medidas autoaplicáveis, bastou aos respondentes seguir as orientações dadas no questionário, não sendo necessário nenhum tipo de intervenção dos aplicadores. Mesmo assim, caso fosse solicitado, os aplicadores deveriam prestar unicamente esclarecimentos quanto à forma, e nunca quanto ao conteúdo dos itens. Ao fim da aplicação, foi deixado um endereço eletrônico no qual os participantes podem obter informações adicionais acerca do estudo.

\section{Análise}

Após coletados, os dados foram tabulados por meio do pacote estatístico SPSS 15.0 (Statistical Package for the Social Sciences). Além das estatísticas descritivas (frequência, média, etc.), foram efetuadas por meio desse programa Testes $t$ de Student com o propósito de comparar as pontuações médias apresentadas pelos respondentes em função do sexo e dos tipos de universidades (pública e privada).

\section{Resultados e discussões}

Neste item, serão demonstrados os resultados da pesquisa realizada com universitários das redes pública e privada acerca de suas atitudes frente aos profissionais de limpeza urbana. Foram aplicadas três escalas, a saber: uma de atitudes, uma de motivação interna e externa para responder sem preconceito e outra de desejabilidade social.

A seguir, apresentam-se os resultados das duas primeiras escalas em comparação ao sexo. Nestas, pretendeu-se verificar as diferenças de atitudes e motivações de homens e mulheres quanto aos garis. As duas escalas foram reduzidas a dois fatores cada: atitudes positivas e negativas e motivações internas e externas para responder sem preconceito.

Tabela 2. Comparação quanto às médias dos domínios das 2 escalas em relação ao sexo

\begin{tabular}{llllll}
\hline & Sexo & Media & Dp & $t$ & P \\
\hline Atitudes positivas & Masculino & 3,35 & 836 & & \\
& Feminino & 3,68 & 694 & 3,02 & 0,03 \\
Atitudes negativas & Masculino & 1,64 & 516 & & \\
& Feminino & 1,52 & 517 & 1,56 & 0,11 \\
Motivação externa & Masculino & 3,94 & 2,256 & & \\
& Feminino & 3,30 & 2,120 & 2,05 & 0,04 \\
Motivação interna & Masculino & 6,24 & 1,431 & & \\
& Feminino & 6,61 & 1,075 & 2,09 & 0,03 \\
\hline
\end{tabular}


Quanto às atitudes, Rodrigues ressalta que elas envolvem o que as pessoas pensam, sentem e como gostariam de se comportar a respeito de um objeto atitudinal. Neste contexto, como detalha a tabela, as mulheres apresentam mais atitudes positivas e motivação interna quanto ao gari, o que indica que elas agem preconceituosamente com o gari em menor índice do que os homens, bem como apresentam uma base de motivações que independem das motivações e das influências externas do meio ou são influenciadas por estas de modo ínfimo.

Já os homens apresentam mais atitudes negativas e motivações externas em relação ao gari, o que sugere que eles se importam mais com as normas politicamente corretas e com a manutenção da boa imagem perante a sociedade. Conforme Rodrigues, tais índices encontram fundamentação na perspectiva de que o comportamento é determinado não apenas pelo que as pessoas gostariam de fazer, mas também pelo que elas pensam que devem fazer, tendo em vista as consequências esperadas de seu comportamento.

Tais médias revelam que as estudantes do sexo feminino são mais conscientes do que os do sexo masculino quanto à importância da profissão de gari para o bom funcionamento urbano, conforme se pode constatar na significância da margem de erro, que foi inferior a 0,05, no que se refere às atitudes positivas e às motivações externas e internas.

Quanto às atitudes dos estudantes dos dois sistemas universitários (público e privado), como se observa no Quadro III, tem-se que os estudantes de rede particular apresentam mais atitudes positivas em relação ao gari quando comparados aos estudantes de rede pública, bem como apresentam maior índice de motivação interna quando comparados a eles, embora tais escores não sejam representativos.

Tabela 3. Tipo de universidade x médias dos domínios das 2 escalas

\begin{tabular}{llllll}
\hline Tipo de Universidade & Média & Dp & T & P \\
\hline Atitudes positivas & Pública & 3,35 & 836 & & \\
& Privada & 3,68 & 694 & 1,00 & 0,31 \\
Atitudes negativas & Pública & 1,64 & 516 & & \\
& Privada & 1,52 & 517 & 0,40 & 0,68 \\
Motivação externa & Pública & 3,94 & 2,256 & & \\
& Privada & 3,30 & 2,120 & 0,37 & 0,70 \\
Motivação interna & Pública & 6,24 & 1,431 & & \\
& Privada & 6,61 & 1,075 & 0,36 & 0,71 \\
\hline
\end{tabular}

Tal índice derruba a hipótese de que estudantes de universidades públicas relacionariam mais atributos positivos à profissão de gari do que os estudantes de universidades privadas. Essa proposição é ainda reforçada pela média de atitudes negativas e pela motivação externa apresentada pelos estudantes da rede pública, superior aos da rede particular.

Conforme Pager, a sondagem de atitudes por meio de pesquisas de campo constitui um método eficaz para mensurar os diferentes graus de discriminação, embora o mesmo implique vantagens e limitações devido ao fato de que a discriminação, no contexto atual, se apresenta de modo sutil. E é com essa sutileza que o preconceito se instala nas relações sociais e na construção da 
imagem do outro, mas que ainda assim se apresenta como dilacerador da identidade alheia. $\mathrm{Na}$ perspectiva de Santos et al., o preconceito se dá de modo sutil, uma vez que as normas sociais se opõem ao preconceito e exercem sobre as pessoas uma autoridade que limita manifestações muito expostas.

Por sua sutileza, pode-se compreender o fenômeno da invisibilidade pública como uma forma de manifestação do preconceito. Objeto de estudo de Costa, tal fenômeno é uma construção e expressão do fenômeno psicossocial da humilhação, que age de modo externo, como um golpe público, e continua agindo por dentro, como uma angústia de não sentir-se visto como ser, para além do ofício que ocupa. Tal invisibilidade apresenta-se como uma posição não natural em que "um homem pode ser submetido, forma-se entre cegos superiores e subalternos invisíveis" (2004, p. 156).

Abaixo segue um gráfico ilustrativo com a frequência dos universitários quanto à desejabilidade social, no qual se pode perceber que 57 estudantes de rede pública apresentam conduta não desejável socialmente, enquanto 65 estudantes da rede particular apresentam a não desejabilidade, sendo mais representativo nesse sentido.

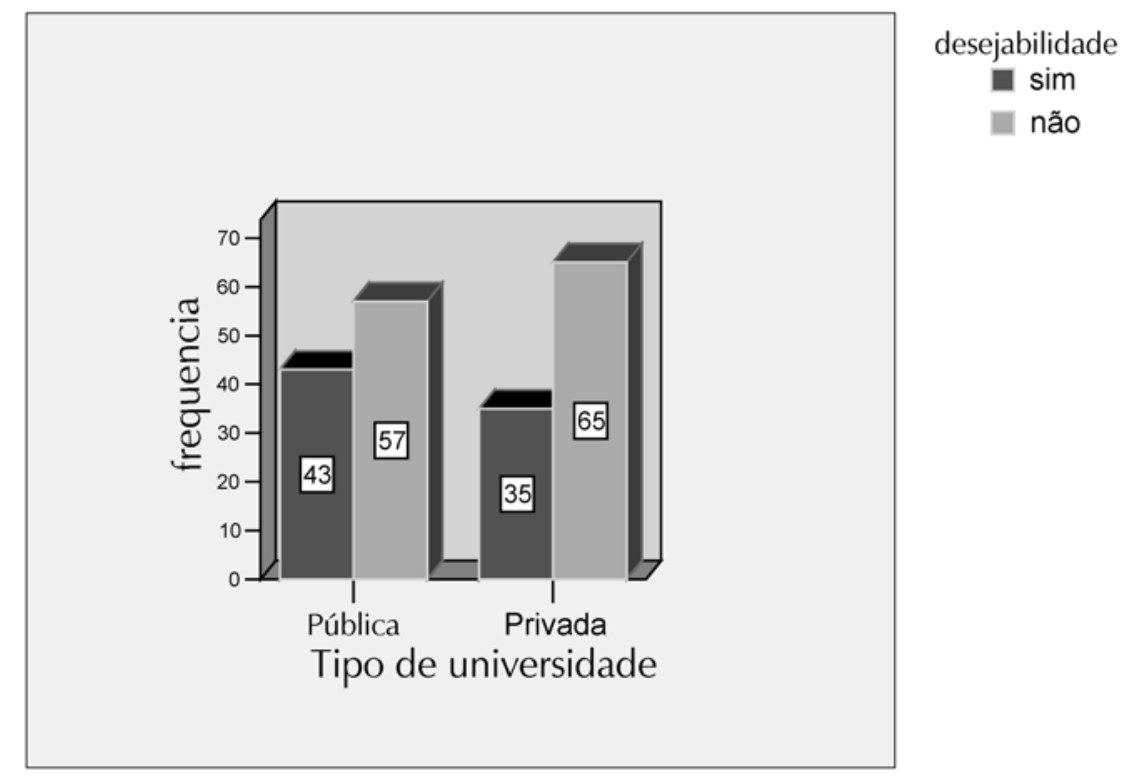

Figura 1. Frequência de desejabilidade e tipo de universidade

A desejabilidade social corresponde à tendência que o indivíduo tem de apresentar respostas socialmente aceitáveis ou consideradas corretas, que modo que viabilize sua aprovação pelos outros. Contanto que sejam socialmente aprovadas, tais respostas não correspondem necessariamente à posição verdadeira que o indivíduo assume em sua vida e em suas relações com o outro; o importante, nesse caso, é negar qualquer associação pessoal a opiniões ou a comportamentos socialmente desaprovados.

Nessa perspectiva, Amodio et al. (2003 como citado em Gouveia et al., 2006), preceituam que as pessoas internamente motivadas para responder sem preconceitos são guiadas por interesses pessoais, enquanto aquelas com motivações externas tendem a ser orientadas pelo interesse de 
como podem parecer na percepção dos outros, o que sugere que estas agem com fortes indícios de desejabilidade social. Já Plant e Devine (1998 como citado em Gouveia et al., 2006) indicam que as pessoas motivadas a responder sem preconceito tendem a apresentar ligeiramente mais preconceito do que aquelas que são motivadas internamente.

Com relação às áreas dos cursos universitários, como se observa no Quadro IV, tem-se que apenas a média de motivação externa para responder sem preconceito foi estatisticamente significativa $(0,017)$, com maior índice sendo verificado na área de exatas, ou seja, há nos alunos dessa área uma predominância de postura que objetiva aprovação social, sem que, entretanto, apresentem um índice considerável de atitudes positivas com relação ao gari.

Tabela 4. Curso x médias dos domínios das 2 escalas

\begin{tabular}{llllll}
\hline & Curso & Média & Dp & F & P \\
\hline Atitudes positivas & Humanas & 3,59 & 771 & & \\
& Exatas & 3,28 & 840 & & \\
& Saúde & 3,56 & 739 & 2,167 & 117 \\
Atitudes negativas & Humanas & 1,54 & 566 & & \\
& Exatas & 1,67 & 417 & & \\
& Saúde & 1,58 & 482 & 773 & \multirow{2}{*}{463} \\
Motivação externa & Humanas & 3,38 & 2,228 & & \\
& Exatas & 4,57 & 2,060 & & \\
& Saúde & 3,43 & 2,113 & 4,143 & 0,017 \\
& Humanas & 6,35 & 1,310 & & \\
& Exatas & 6,62 & 1,309 & & \\
& Saúde & 6,50 & 1,144 & 674 & 511 \\
\hline
\end{tabular}

Nesse sentido, a motivação externa para responder sem preconceito funciona como um tipo da desejabilidade social, uma vez que o sujeito tende a responder sem preconceito mais para ser aceito socialmente do que para confirmar sua motivação interna. Rivera (2009) corrobora esse resultado ao afirmar que as pessoas tendem a experimentar, em nível consciente ou inconsciente, um conflito psicológico devido ao confronto entre suas atitudes íntimas preconceituosas e as normas sociais externas contra o preconceito, o que as leva a adotar as respostas socialmente aprovadas e a manifestar, em atitudes, um preconceito mais camuflado e sutil.

Quanto à relação entre atitudes, motivação e idade, como ilustra a Tabela $\mathrm{V}$, tem-se que os estudantes com idades entre 18 e 30 anos, o que corresponde a 94,5\% do total de estudantes da amostra, apresentam maior média de atitudes positivas e de motivação externa para responder sem preconceito em relação ao profissional de limpeza urbana, o que, conforme Allport, indica que há diferenças entre os erros dos pré-julgamentos e os do preconceito, de modo que, se uma pessoa é capaz de corrigir um julgamento errôneo e de levar em consideração uma nova evidência, esse julgamento pode ser considerado preconceito. Por isso, os pré-julgamentos só se tornam preconceitos se não forem reversíveis quando expostos a novos conhecimentos. Tal afirmação nos leva a inferir que estudantes dessa faixa etária, por serem mais jovens e ainda não terem conceitos notadamente rígidos e cristalizados, estão mais abertos para mudar de posição 
ideológica e de ações perante um determinado objeto, reconhecendo assim, de algum modo, a importância e o valor dessa profissão.

Tabela 5. Idade e médias dos fatores

\begin{tabular}{llllll}
\hline & Idade & Média & Dp & T & P \\
\hline Atitudes positivas & Entre 18 E 30 Anos & 3,53 & 776 & & \\
& Entre 30 E 54 Anos & 3,42 & 841 & 0,47 & 0,63 \\
\multirow{4}{*}{ Atitudes negativas } & Entre 18 E 30 Anos & 1,56 & 500 & & \\
& Entre 30 E 54 Anos & 1,82 & 767 & 1,59 & 0,11 \\
\multirow{4}{*}{ Motivação externa } & Entre 18 E 30 Anos & 3,61 & 2,205 & & \\
& Entre 30 E 54 Anos & 3,45 & 2,222 & 0,22 & 0,82 \\
& Entre 18 E 30 Anos & 6,45 & 1,259 & & \\
& Entre 30 E 54 Anos & 6,27 & 1,336 & 0,45 & 0,65 \\
\hline
\end{tabular}

Já os estudantes de faixa etária entre 30 e 54 anos apresentam maior índice de atitudes negativas e menor índice de motivação interna. Seguindo a ideia de Suman (2007), há um problema evidente quando as pessoas, mesmo a par de novas informações que podem modificar os preconceitos já enraizados, continuam compreendendo e enxergando com maior coerência as ideias que já têm concebidas e enraizadas, ou seja, por serem mais velhos se comparados ao primeiro grupo, possuem ideias mais rígidas e menos passíveis de mudanças.

No entanto, em detrimento da maior ou menor cristalização das posturas a respeito de determinado objeto, em função da experiência de vida, e embora os fatores (motivações e atitudes) tenham apresentado poucas diferenças, pode-se inferir, a partir desses dados, que o fator idade não interfere nas atitudes assumidas pelo indivíduo.

\section{Considerações finais}

Por se tratar de uma pesquisa quantitativa, a natureza dos resultados obtidos atingiu os objetivos propostos e demonstrou, em termos gerais, que este estudo apresentou resultados positivos com relação à atitude dos universitários de redes tanto pública quanto privada, não apresentando diferenças significativas entre elas, o que demonstra que, em ambas, os universitários apresentam atitudes positivas com relação aos profissionais de limpeza urbana, embora também demonstrem índices de motivações externas para responder sem preconceito.

Entretanto, no que tange ao gênero, encontrou-se diferença quanto às atitudes em relação ao profissional gari, em que as mulheres possuem atitudes mais positivas, ao passo que mostraram predisposição para responder sem preconceito por motivações internas, demonstrando mais tolerância em relação a essa categoria social do que os homens.

Verificou-se também que, nessa amostra, a idade não foi um fator que se relacionou com atitudes em relação ao gari, porém a área em que seus cursos estão inseridos mostrou um fator relacional com a motivação em responder sem preconceito, demonstrando que os alunos que cursam a área de exatas ancoram suas motivações no mundo social, o que evidencia mais desejabilidade social, provavelmente por seus cursos não focarem conteúdos subjetivos e humanos. 
Foram encontradas algumas limitações por parte dos pesquisadores quanto às dificuldades para comprovar as hipóteses propostas, a saber: apenas a que se refere à diferença entre os sexos no reconhecimento do ofício de gari foi corroborada, pois os estudantes do sexo feminino demonstraram, através das médias avaliadas, terem mais atitudes positivas e motivação interna em relação ao gari. Já a hipótese de que os estudantes de rede pública relacionariam mais atributos positivos com relação ao gari do que os de rede particular não foram corroborados, tendo-se encontrado resultados opostos.

Os resultados obtidos também foram apoiados e justificados pelas teorias trabalhadas na fundamentação teórica, embora esse subsídio teórico não tenha contemplado a proposta da terceira hipótese, que se propunha a avaliar a importância atribuída pelos universitários ao ofício de gari, que não exige formação acadêmica.

Espera-se que esta pesquisa contribua para a ampliação dos escassos subsídios teóricos referentes a estudos sobre esses e outros profissionais, que, embora imprescindíveis para o bom funcionamento urbano, ainda são alvo de atitudes negativas e de discriminação. Por fim, propõe-se uma reflexão sobre a temática abordada, lançando o questionamento sobre o "quanto não seria exigido de nós e de nosso mundo se conversássemos com os garis como conversamos com gente, apenas por reconhecê-las e admiti-los como gente" (Costa, 2004, p. 122). 
Noêmia Soares Barbosa Leal

Graduada em Psicologia pelo Centro Universitário de João Pessoa, João Pessoa - PB - Brasil.

E-mail: noemia.barbosa@hotmail.com

\section{Mário Florentino Soares}

Graduado em Psicologia pelo Centro Universitário de João Pessoa, João Pessoa - PB - Brasil.

E-mail: mariofsoares@hotmail.com

\section{Ivania Tavares da Rocha}

Graduada em Psicologia pelo Centro Universitário de João Pessoa, João Pessoa - PB - Brasil.

E-mail: ivaniatavares@hotmail.com

\section{Cristiane Galvão Ribeiro}

Doutora em Psicologia Social pela Universidade Federal da Paraíba e docente do Centro Universitário de João Pessoa, João Pessoa - PB - Brasil.

E-mail: cristianegr@ig.com.br

\section{Endereço para envio de correspondência:}

Rua Estudante Manoel Soares Lima Filho, 29, ap. 401A, Bancários. CEP: 58051-005. João Pessoa, PB. 


\section{Referências}

Allport, G. W. (1954). The nature of prejudice. Massachusetts: Adisson-Wesley.

Álvaro, J. L., \& Garrido, A. (2006). Psicologia social - perspectivas psicológicas e sociológicas. São Paulo: McGraw-Hill.

Billing, M. (1986). Racismo, prejuicio y discriminación. In S. Moscovici. Psicologia Social II (pp.575-595). Barcelona: Paidós.

Brown, R. (1995). Prejudice: It's social psycology. Oxford: Blackwell.

Camino, L., Maciel, C., Brandão, C., \& Gomes, G. O. (1996) O conhecimento do outro: primeiras explicações em termos de percepção social. In L. Camino (Org.), Conhecimento do outro e a construção da realidade social: uma análise da percepção e da cognição social (pp. 17-58). João Pessoa, PB: Editora Universitária UFPB.

Camino, L., Pereira, C. (2002). O papel da psicologia na construção dos direitos humanos: análise da teorias e práticas psicológicas na discriminação ao homossexualismo. Perfil, 13, 49-49.

Costa, F. B. da. (2004). Homens invisíveis: relatos de uma humilhação social. São Paulo: Globo.

Crowne, D. \& Marlowe, D. (1960). A new scale of social desirability independent of psychopathology. Journal of Consulting Psychology, 24(4), 349-354. doi: 10.1037/ h0047358

Davidoff, L. L. (1983). Introdução à psicologia. São Paulo: McGraw-Hill do Brasil.

Ferreira, M. C. (2010). A psicologia social contemporânea: principais tendências e perspectivas nacionais e internacionais. Psicologia Teoria e Pesquisa, 26(Spe.), 51-64. doi: http://dx.doi. org/10.1590/S0102-37722010000500005

Gonçalves Filho, J. M. (1998). Humilhação social: um problema político em psicologia. Psicologia USP, 9(2), 11-67. doi: http:// dx.doi.org/10.1590/S0103-65641998000200002

Gouveia, V. V., Souza, M. L. Filho, Araújo, A. G. T., Guerra, V. M., \& Sousa, D. F. M de. (2006).

Correlatos valorativos das motivações para responder sem preconceito. Psicologia: Reflexão e Crítica, 19(3), 422-432. doi: http://dx.doi.org/10.1590/S0102-79722006000300011

Guerra, P. B. de C. (2002). Psicologia social dos estereótipos. PsicoUSF, 7(2), 239-240. doi: http://dx.doi.org/10.1590/ S1413-82712002000200013

Heider, F. (1958/1970). The psychology of interpersonal relations. New York: Wiley.

Jones, J. M. (1973). Racismo e preconceito. São Paulo: Ed. Edgar Blucher.

Katz, D. (1960). The functional approach to the study of attitudes. Public Opinion Quarterly, 24, 163-204. doi: $10.1086 / 266945$

Lima, L. P. (2002). Atitudes: estrutura e mudança. In J. Vala \& M. B. Monteiro (Orgs.), Psicologia social (5a ed., pp. 187-225). Lisboa, Portugal: Fundação Calouste Gulbenkian.

Lima, M. E. O., \& Vala, J. (2004). As novas formas de expressão do preconceito e do racismo. Estudos de Psicologia, 9(3), 401-411. doi: http://dx.doi.org/10.1590/S1413-294X2004000300002
McDavid, J. W., \& Harari, H. (1980). Psicologia e comportamento social. Rio de Janeiro: Interciência.

Martínez, M. C. (1996). Análisis psicosocial del prejuicio. Madri: Editorial Síntesis.

Medeiros, L. F. R. de, \& Macedo, K. B. (2006). Catador de material reciclável: uma profissão para além da sobrevivência? Psicologia e Sociedade, 18(2), 62-71. doi: http://dx.doi.org/10.1590/ S0102-71822006000200009

Melo, G. F. de, Giavoni, A., \& Tróccoli, B. T. (2004). Estereótipos de gênero aplicados a mulheres atletas. Psicologia Teoria e Pesquisa, 20(3), 251-256. doi: http://dx.doi.org/10.1590/ S0102-37722010000500005

Michener, A. H., DeLamater, J. D., \& Myers, D. G. (2005) Psicologia social. São Paulo: Pioneira Thomson Leaening.

Myers, D. G. (2000). Psicologia social (6a ed.). Rio de Janeiro: LTC.

Myers, D. G. (2006). Psicologia (7a ed.). Rio de janeiro: LTC.

Moreira, E. F., Costa, J. B., Raymundo, J. S., \& Araújo, L. F. (2004). Estereótipos sociais de universitários em relação aos ambientalistas. Estudos em Psicologia, Campinas, 21(02), 117-127. doi: http://dx.doi.org/10.1590/S0103166X2004000200009

Pager, D. (2006). Medir a discriminação. Tempo Social, 18(2), 65-88. doi: http://dx.doi.org/10.1590/S0103-20702006000200004

Pisani, E. M., Bisi, G. P., Rizzon, L. A., \& Nicoletto, U. (1985). Psicologia geral (5a ed.). Porto Alegre: Vozes.

Plant, E. A., \& Devine, P. G. (1998). Internal and external motivation to respond without prejudice. Journal of Personality and Social Psychology, 75(3), 811-832. doi: 10.1037/0022-3514.75.3.811

Reimberg, C., Barcellos, P., \& Bossle, D. (2007). Preconceito afeta trabalho de garis. São Paulo: Proteção. Recuperado em 10 de maio, 2008 de http://www.protecao.com.br/novo/imgbanco/ imagens/Re-Suplemento-SP/SuplementoSP/fev-07.pdf

Rivera, G. A. (2009). As novas formas de racismo e os valores sociais. (Dissertação de Mestrado). Programa de Pós-Graduação em Psicologia Social, Universidade Federal da Paraíba, João Pessoa, PB.

Rodrigues, A. (1998). Psicologia social (12a ed.). Petrópolis, RJ: Vozes.

Rodrigues, A., Assmar, E. M. L., \& Jablonski, B. (2001) Psicologia social. Rio de Janeiro: Vozes.

Santos, W. S. dos, Gouveia, V. V., Navas, M. S., Pimentel, C. E. \& Gusmão, E. E. da S. (2006). Escala de racismo moderno: adaptação ao contexto brasileiro. Psicologia em Estudo, Maringá, 11(3), 637-645. doi: http://dx.doi.org/10.1590/ S1413-73722006000300020

Suman, R. B. (2007). Catadores de lixo: estereótipos sociais sobre sua atividade e relação com a escola - um estudo de caso. Cadernos Ceru, 18, 1-20. Recuperado em 12 abr., 2008 de http:// serviços.caps.gov.br/capsdw/resumo.html?idtese $=200$ 58933017018007p8// 